\title{
The Effect of Beijing-Shanghai High-Speed Railway on the Economic Development of Prefecture-Level Cities Along the Line Based on DID Model
}

\author{
Ma Yuzhou ${ }^{1}$ \\ ${ }^{1}$ School of Economics and Management, Beijing Jiaotong University, Beijing, China
}

\begin{abstract}
High-speed railway has an essential impact on the economic and social development of the regions along the line. Based on the Beijing-Shanghai high-speed railway, this paper constructs the DID model and analyzes the impact of Beijing-Shanghai high-speed railway on the economic development of prefecture-level cities along the route from the empirical perspective. The empirical analysis results show that the BeijingShanghai high-speed railway has a significant negative impact on the per capita GDP of prefecture-level cities along the line in the short term, mainly because the agglomeration effect is greater than the diffusion effect. Therefore, small cities should actively think about how to deal with the agglomeration effect caused by the construction of high-speed rail.
\end{abstract}

\section{Introduction}

Since the opening of Beijing-Tianjin intercity high-speed railway in 2008, China's high-speed railway (abbreviated to "HSR", for short) has stepped into a rapid expansion stage, and the "four vertical and four horizontal" HSR network planned and constructed by the state has taken shape. The medium- and long-term railway network planning (2016-2025) issued in 2016 further elaborated the requirements in the new HSR era in order to meet the exceeding fast increase of passenger transport demand and expand the regional development space. Eventually form a "eight vertical and eight horizontal" HSR network based on "four vertical and four horizontal" HSR network, linked by regional connection line and supplemented by the intercity railway. Regardless of the technical level, construction scale or operation mileage, China's HSR is far ahead of other countries, leading the new development of the HSR in the world. HSR has become a business card of China image and transportation technology innovation, promoting the flow of people, goods and information among cities along the line, strengthening regional cooperation, and also driving the academic research passion on HSR.

Beijing-Shanghai high-speed railway (abbreviated to "BSHSR", for short) is the "second vertical" in the "eight vertical and eight horizontal" network. It starts from Beijing and ends in Shanghai with 24 stations, spanning Beijing, Tianjin, Hebei, Shandong, Anhui, Jiangsu and Shanghai, three municipalities directly under the central government and four provinces. Fig. 1 shows the line. BSHSR officially opened to traffic on June 30, 2011. Its total length is 1318 kilometers, running velocity is 300 kilometers per hour, and total investment excesses 220.94 billion yuan. The line is a project with the most massive scale and highest technique since the founding of China. The BSHSR, which owns faster speed, fewer stops, and more running trains, adds a vital passenger transport channel for the eastern region. BSHSR improves the transportation capacity of Beijing-Shanghai line, meets the ever-growing travel demand of passengers, and strengthens the connection between the two urban clusters of "Beijing Tianjin Hebei" and "Yangtze River Delta." Meanwhile, the open of BSHSR relieves the pressure and eases the tension of the passenger transport capacity for the existing Beijing-Shanghai railway. It is also conducive to the transfer of advantage industries from the eastern regions to the central and western regions, the radiation of economic advantages in the eastern region to the whole country, and the revitalization of the national economy.

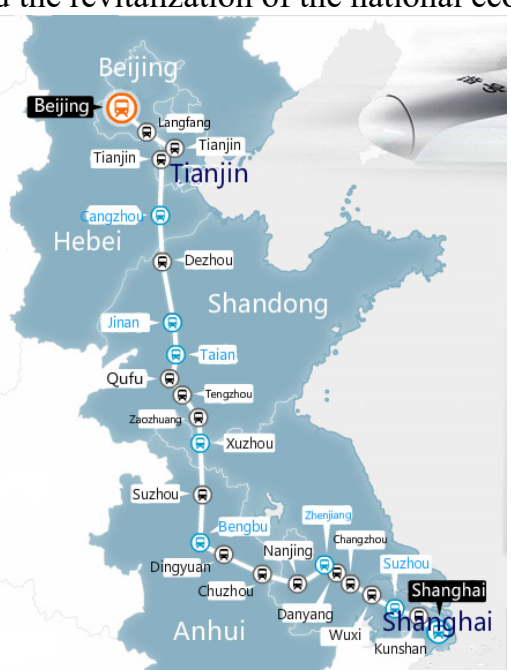

Fig1. Route Map of BSHSR 


\section{Literature Review}

There is no unified view on the effect of the HSR on regional economic growth along the line, and it can be positive or negative. Scholars at home and abroad mainly hold two views. One view is that the effect is positive. The HSR can improve accessibility, compress space-time distance, eliminate communication barriers, promote the flow of elements, and eventually realize economic growth. Ahlfeldt and Feddersen (2010) took the HSR from Cologne to Frankfurt as the work subject and researched its influence on the economy in terms of economic geography. By driving economic agents nearer and improving accessibility, HSR can promote regional economic growth. Countryside adjacent to Limburg and Montabaur, two intermediate stops, experienced a 2.7\% level lift in GDP after the construction of CologneFrankfurt HSR because of the exogenous variation of accessibility. The economic growth elasticity of market accessibility is 0.25 , and this effect prolongs in the long term [1]. Fang and Sun (2016) research the Yangtze River Delta Urban Cluster, using the data of cities at prefecturelevel and DID method. They conclude that in the short term, the HSR can promote the economic growth of the Yangtze River Delta Urban Cluster, but it can expand the urban-rural disparity to a certain extent [2]. Jia, Zhou, and Qin (2017) adopt DID and PSM-DID methods to study the economic impact of the HSR under the hypothesis of nonhomogeneous space. The results show that HSR can promote economic growth and reshape the structure of China's economy in space level. However, the HSR effect verifies in different lines [3]. Li, Fan, and Zhang (2020) analyze the spatial spillover effect of HSR on the real economy in four districts of China by establishing a dynamic spatial Durbin model. The empirical results demonstrated the following: due to the structural imbalance between the real economy and virtual economy, the spatial spillover effect in the eastern district is low. However, HSR possesses a long-range real economy promotion effect for the provinces along the railway; we can spot the sustained effect in the northeast district; while there is no noticeable effect in the western district at the early stage due to resource constraints [4].

The other view is that the HSR fails to promote the economy in the alongside cities. Because of the characteristics of the enormous cost and long payback period, HSR increases the risk of local government missing the development opportunities of other industries and overdrafts the regional potential. Although the HSR can increase the accessibility and competitive advantages in the underdeveloped region to some extent, the industrial agglomeration and economic growth brought by the HSR in developed areas may be more significant, which will maintain or even expand the regional disparity. In the study of the network development of French TGV, Germany ICE, Italy direttissima, and Spain AVE, Vickerman (1997) deem that different access points gain different accessibility on the network of HSR depending on their position. He points out that HSR inevitably facilitates the expansion of the core area at a expense of sacrificing the opportunity of the periphery area to progress, thereby damaging the periphery area economy
[5]. Using the 2006-2010 data of the 287 cities in China and the DID estimation method, Wang and Nian (2014) test what influence can HSR bring to the regional economy. The results show that HSR do not act the leading role in promoting regional economic growth in a short time in the context of the Chinese economy slows down recently [6]. Using the 2001-2012 panel data of prefecture-level city and two-way fixed effect model, Zhang and Tao (2016) confirmed the existence of the agglomeration effect of HSR. Moreover, the opening of HSR reduces the economic growth rate of prefecture-level cities along the line by agglomeration effect and squeezing fixed asset investment, and the nearer the small cities are to the regional central cities, the more negative impact it has [7]. Wang, Meng, and Hou (2020) obtain a finding by acquiring "night lighting data" as their critical economic indicators and the PSM-DID method, which is that HSR fails to promote the economic growth of cities along HSR in the short term, but accelerated the economic diffusion in the long term [8].

\section{Research Methods and Data Sources}

\subsection{Difference in Difference}

One of the challenges to studying the impact of HSR on regional economic growth is the endogenous problem caused by the reverse causality between the opening of HSR and regional economy. As a strategic plan at the national level, HSR is mainly connected with regional central cities, forming a crisscross HSR network. For the non-regional central cities along the line, whether to open HSR mainly depends on whether its location is on the connection between the central cities. Therefore, the cities' economic growth along the line is not the immediate cause to determine whether the HSR passes through the city. We select the cities along the BSHSR as the research objects, which largely avoids the endogenous problems caused by the reverse causality.

The implementation of a project will affect some groups in the society, while the other groups may not be affected, or the impact is limited, so the implementation of this project can be analogous to some treatment imposed on the subjects in natural science experiments. The double-difference method often uses for the quantitative evaluation of the effect of public projects or policies, which can divide into different groups, and the evaluation results have explanatory power and robustness. An HSR project is a public project. Its implementation will inevitably have an impact on regional economic development, and the impact varies in different regions. The DID model can use for our analysis. Equation (1) shows the basic DID model established in this paper:

$$
\begin{aligned}
& Y_{i t}=\beta_{0}+\beta_{1} \text { group }_{i}+\beta_{2} \text { period }_{t}+\beta_{3} \text { group }_{i} \times \text { period }_{t} \\
& +\beta_{4} X_{i t}+\varepsilon_{i t}
\end{aligned}
$$

In this model, $Y_{i t}$ represents the economic indicators of the prefecture-level city $i$ in the period $\mathrm{t} ; i$ represents every sample city including the treatment group and the control group; $t$ represents the year from 2008 to 2014; group $_{i}$ is the virtual variable of the group, which indicates whether the city is a station city of BSHSR. The value of non- 
station cities along the line (control group) is 0 , and the value of station cities (treatment group) is 1 ; period $_{t}$ is the virtual variable of time, indicating whether the BSHSR is open to traffic in that year. The value before opening to traffic is 0 , and the value after opening to traffic is 1 ; the interaction term group $_{i} \times$ period $_{t}$ represents the virtual variable of whether the city opens HSR in a particular year; $X_{i t}$ represents the control variable matrix, including a series of other indicators affecting economic development; $\varepsilon_{i t}$ represents random error term. The coefficient of interaction term $\beta_{3}$ reflects the HSR effect, which is also the most concerned coefficient in this paper. If $\beta_{3}$ is positive and passes the significance test, which indicates that the opening of the BSHSR has a positive effect in promoting the economic development of the cities along the line; otherwise, the effect is negative.

\subsection{Data Source}

This paper selects 29 prefecture-level cities in four provinces that BSHSR passes through as sample cities. The empirical analysis adopts these cities' panel data from 2008 to 2014, which comes from China Urban Statistical Yearbook 2009-2015. The software for analysis is stata16.

\section{Empirical Analysis}

\subsection{Sample City Selection}

With the rapid development of China's HSR, there are other HSR lines, such as Beijing-Guangzhou HSR, in three municipalities and four provinces where BSHSR passes through. Many prefecture-level cities have opened HSR lines, especially in the past two years. In order to minimize the impact of other HSR lines on the accuracy of the model, this paper selects a relatively earlier time cut-off point - December 31, 2014. Table 1 shows the HSR opening status of these cities before the time cut-off point, according to the division of administrative regions.

Table1. the HSR opening status of these prefecture-level cities in 2014/12/31

\begin{tabular}{|c|c|c|}
\hline Province & Open & Unopen \\
\hline Beijing & Beijing & \\
\hline Tianjin & Tianjin & \\
\hline Shanghai & Shanghai & \\
\hline Hebei & $\begin{array}{c}\text { Shijiazhuang, Baoding, } \\
\text { Tangshan, Cangzhou, } \\
\text { Xingtai, Handan, } \\
\text { Qinhuangdao }\end{array}$ & $\begin{array}{c}\text { Zhangjiakou, Chengde, } \\
\text { Hengshui }\end{array}$ \\
\hline Shandong & $\begin{array}{l}\text { Jinan, Qingdao, Yantai, } \\
\text { Weifang, Zibo, Tainan, } \\
\text { Zaozhuang, Dezhou }\end{array}$ & $\begin{array}{l}\text { Liaocheng, Heze, Linyi, } \\
\text { Rizhao, Dongying, } \\
\text { Binzhou, Laiwu, } \\
\text { Weihai, Jining }\end{array}$ \\
\hline Anhui & $\begin{array}{c}\text { Hefei, Chuzhou, Bengbu, } \\
\text { Liuan, Suzhou, Huainan, } \\
\text { Chizhou }\end{array}$ & $\begin{array}{l}\text { Haozhou, Fuyang, } \\
\text { Huaibei, Xuancheng, } \\
\text { Maanshan, Wuhu, } \\
\text { Tongling, Anqing, } \\
\text { Huangshan } \\
\end{array}$ \\
\hline
\end{tabular}

\begin{tabular}{|c|c|c|}
\hline Jiangsu & $\begin{array}{c}\text { Suzhou, Wuxi, } \\
\text { Changzhou, Zhenjiang, } \\
\text { Nanjing, Xuzhou }\end{array}$ & $\begin{array}{c}\text { Huaian, Lianyungang, } \\
\text { Taizhou, Suqian, } \\
\text { Yangzhou, Nantong, } \\
\text { Yancheng }\end{array}$ \\
\hline
\end{tabular}

The treatment group is the prefecture-level cities that BSHSR passes through, including Cangzhou, Langfang, Zaozhuang, Tai'an, Dezhou, Bengbu, Chuzhou, Suzhou, Wuxi, Xuzhou, Changzhou, Suzhou and Zhenjiang. The selection standard of the control group set as the prefecture-level cities with similar economic volume and development trend as the treatment group but without HSR, which are selected from the Unopen column in Table 1. The control group includes Chengde, Hengshui, Laiwu, Linyi, Liaocheng, Heze, Huaibei, Fuyang, Xuancheng, Nantong, Lianyungang, Huai'an, Yancheng, Yangzhou, Taizhou and Suqian.

\subsection{Variable Declaration}

Considering the availability and representativeness of data, we select the per capita GDP of prefecture-level cities in 2008-2014 as the explained variable. Explanatory variables include grouping dummy variable, time dummy variable, interaction item. For the selection of control variables, referring to the summary of economic growth factors by Steven N. Durlauf et al. (2004), this paper considers the input of production factors, transportation factors and other factors. Finally, the control variables chose fixed asset investment (representing capital investment), the number of employees (representing labour investment), road area (representing traffic factors), financial expenditure and industrial structure. In order to reduce data fluctuation and eliminate heteroscedasticity, variables are treated by logarithm except for industrial structure. Table 2 and Table 3 show the specific description and descriptive statistics of these variables.

Table2. Variable Description

\begin{tabular}{|c|c|}
\hline Variable & Declaration \\
\hline lnpergdp & $\begin{array}{c}\text { gross regional product per } \\
\text { capita after taking logarithm }\end{array}$ \\
\hline group & virtual variable of group \\
\hline period & virtual variable of time \\
\hline group $\times$ period & interaction term \\
\hline lninv & $\begin{array}{c}\text { regional fixed asset investment } \\
\text { after taking logarithm }\end{array}$ \\
\hline lnworker & $\begin{array}{c}\text { number of employees after } \\
\text { taking logarithm }\end{array}$ \\
\hline lnroad & $\begin{array}{c}\text { road area after taking logarithm } \\
\text { regional financial expenditure } \\
\text { after taking logarithm }\end{array}$ \\
\hline lnfin & regional industrial structure \\
\hline indstr
\end{tabular}

Table3. Descriptive statistics

\begin{tabular}{|c|c|c|c|c|}
\hline Variable & Mean & $\begin{array}{c}\text { Standard } \\
\text { Deviation }\end{array}$ & Minimum & Maximum \\
\hline lnpergdp & 10.43158 & 0.6302261 & 8.775704 & 12.20115 \\
\hline group & 0.4482759 & 0.4985469 & 0 & 1 \\
\hline period & 0.5714286 & 0.4960951 & 0 & 1 \\
\hline
\end{tabular}




\begin{tabular}{|c|c|c|c|c|}
\hline group $\times$ period & 0.2561576 & 0.437589 & 0 & 1 \\
\hline lninv & 16.20235 & 0.7104116 & 14.45166 & 17.91881 \\
\hline lnworker & 12.92445 & 0.5839887 & 11.65962 & 14.96425 \\
\hline lnroad & 16.5887 & 0.6231449 & 14.93719 & 18.22916 \\
\hline lnfin & 14.56908 & 0.6781622 & 12.88364 & 16.84153 \\
\hline indstr & 0.7149765 & 0.1437196 & 0.3749627 & 1.114502 \\
\hline
\end{tabular}

\subsection{The Establishment of DID Model}

Equation (2) shows the complete DID model.

\section{$Y_{i t}=\beta_{0}+\beta_{1}$ group $_{i}+\beta_{2}$ period $_{t}+\beta_{3}$ group $_{i} \times$ period $_{t}$ $+\beta_{4}$ Ininvit $_{i t}+\beta_{5}$ Inworker $_{i t} \quad+\beta_{6}$ Inroad $_{i t} \quad+\beta_{7}$ Infin $_{i t}$ $+\beta_{\text {sindstrit }}+\varepsilon_{i t}$

Next procedure is to determine the optimal form of the model. This paper uses these panel data and establish the mixed model (POLS), fixed effect model (FE) and random effect model (RE) separately, then conducts F-test and Hausmann test in turn. Table 4 shows the specific test results.

Table4. POLS, FE and RE results

\begin{tabular}{|c|c|c|c|}
\hline Variable & POLS & FE & RE \\
\hline group & $\begin{array}{c}0.188684 \\
(2.63) * * *\end{array}$ & $\begin{array}{l}0 \\
(.)\end{array}$ & $\begin{array}{c}0.2519231 \\
(2.14) * *\end{array}$ \\
\hline period & $\begin{array}{l}0.3050282 \\
(4.44) * * *\end{array}$ & $\begin{array}{c}0.202181 \\
(6.60) * * *\end{array}$ & $\begin{array}{l}0.2007405 \\
(6.37) * * *\end{array}$ \\
\hline group $\times$ period & $\begin{array}{c}-0.160302 \\
(-1.71)^{*}\end{array}$ & $\begin{array}{l}-0.0844506 \\
(-2.68) * * *\end{array}$ & $\begin{array}{l}-0.0892659 \\
(-2.66) * * *\end{array}$ \\
\hline $\operatorname{lninv}$ & $\begin{array}{c}0.8259266 \\
(10.49) * * *\end{array}$ & $\begin{array}{l}0.1952182 \\
(4.11) * * *\end{array}$ & $\begin{array}{l}0.2367732 \\
(4.82) * * *\end{array}$ \\
\hline lnworker & $\begin{array}{c}-0.0356394 \\
(-0.44)\end{array}$ & $\begin{array}{c}0.0699783 \\
(1.80) *\end{array}$ & $\begin{array}{c}0.0729136 \\
(1.7) *\end{array}$ \\
\hline lnroad & $\begin{array}{l}0.3250115 \\
(5.70) * * *\end{array}$ & $\begin{array}{c}0.0976411 \\
(1.97) * * \\
\end{array}$ & $\begin{array}{c}0.1234739 \\
(2.49) * *\end{array}$ \\
\hline $\operatorname{lnfin}$ & $\begin{array}{l}-0.3989128 \\
(-4.77) * * *\end{array}$ & $\begin{array}{c}0.217203 \\
(4.93) * * * \\
\end{array}$ & $\begin{array}{l}0.1789766 \\
(3.88) * * *\end{array}$ \\
\hline indstr & $\begin{array}{c}-0.645496 \\
(-3.48) * * * \\
\end{array}$ & $\begin{array}{c}-0.0224126 \\
(-0.24)\end{array}$ & $\begin{array}{c}-0.0641952 \\
(-0.65) \\
\end{array}$ \\
\hline _cons & $\begin{array}{l}-1.825784 \\
(-2.69)^{* * *}\end{array}$ & $\begin{array}{l}1.502094 \\
(1.98) * *\end{array}$ & $\begin{array}{c}0.8382578 \\
(1.14) \\
\end{array}$ \\
\hline F-Test & - & $\begin{array}{c}F=59.65 \\
p=0.0000\end{array}$ & - \\
\hline Hausman-Test & - & - & $\begin{array}{c}\text { Chi2 }=27.79 \\
\mathrm{p}=0.0002\end{array}$ \\
\hline
\end{tabular}

F-test uses for judging these panel data should use which model, pool or fixed. If the p-value is significant, the fixed effect model is better than the pool model; otherwise, the pool model is better than fixed effect model. Table 4 shows that the data should use the fixed effect model. The Hausmann test uses for judging these panel data should use which model, fixed or random. If the pvalue is significant, the fixed effect model is better than the random effect model; otherwise, the random effect model is better than the fixed effect model. Table 4 shows that the fixed effect model is more suitable compared with the random effect model.

\subsection{Result Analysis}

The coefficient of HSR effect is significantly negative at the level of $1 \%$, indicating that the opening of BSHSR has brought negative impact on per capita GDP of prefecture level cities along the line. According to New Economic Geography, the improvement of regional transportation infrastructure will promote the spatial transfer of economic resources and other factors, that is, economic distribution effect. According to the direction of factor transfer, the distribution effect can be manifested as diffusion effect and agglomeration effect. Diffusion effect refers to that economic factors flow from the central city to the peripheral city due to the high congestion cost and the saturation of human resources. It can reduce the market segmentation of the central city, expand the radiation range of the urban clusters, and mobilize economic vitality of the surrounding areas. The central city possesses resource endowment. Human resources, capital, technologies and materials, these resources are close to it. Agglomeration effect refers to the fact that the opening of the HSR provides a speedy and convenient channel for these factors to swarm into the central city, which accelerates the process of resources gathering in the central city and leads to the fallout of economic growth rate of the circumjacent prefecture-level cities. The combination of these two inverse effects determines the net impact of the opening of BSHSR on the economy of prefecture-level cities. The relative strength of diffusion and agglomeration effect depends on the phase of development in the regional hub city. The net effect of the regional hub city in the rapid development stage is manifested as an agglomeration effect, while a city in a mature stage manifests as a diffusion effect. The regression results show that the central cities along the BSHSR are still in the rapid development stage, and the agglomeration effect is greater than the diffusion effect. Resource scarcity in the peripheral city caused by excessive resources gathering in the central city makes the opening of HSR harms the economic development of prefecture-level cities along the line. Besides, please note that the impact can divide into short-term and long-term impact. This paper bases on the short-term impact, which may be inconsistent with the long-term impact of the opening of HSR.

In terms of the control variables, all of them are in line with expectations, except for the industrial structure. Fixed assets investment and the number of employees at the end of the year have a significant positive effect on the regional per capita GDP. According to the neoclassical growth theory, capital and labour are the two most important factors to promote economic growth. The increase in road area is beneficial to regional per capita GDP. Urban road area represents the development of urban traffic. Urban transportation is a way to transmit the factors of economic development such as people flow and logistics, which can improve the investment environment, enhance the location conditions, and promote the aggregation of regional production factors. Developed urban transportation can also shorten the commuting time, reduce transportation costs, improve economic operation efficiency, and promote regional economic growth. Fiscal 
expenditure is beneficial to the growth of per capita GDP of prefecture-level cities along the line. Fiscal expenditure includes productive expenditure and livelihood expenditure, and its effect on the economy depends on the expenditure structure. As productive expenditure can directly affect the economy, it can also promote economic growth; while livelihood expenditure is likely to operate with lags, so the overmuch livelihood financial expenditure is adverse to the improvement of economic growth rate. Most of the sample cities are in the mediumterm of industrialization, and fiscal expenditure prefers to productive expenditure, so the effect of fiscal expenditure is positive. The upgrading of industrial structure is adverse to the growth of per capita GDP. Contrary to the expectation, this paper is trying to explain it. The effect of the upgrading of industrial structure on economic growth is related to the level of industrialization. Cities in the middle stage of industrialization need the secondary industry to support the economy, while cities in the late stage of industrialization need to adapt to the upgrading of industrial structure. Most of the sample cities are in the middle stage of industrialization, and the excessively rapid upgrading of the industrial structure has some inhibitory effect on economic growth.

\subsection{Parallel Trend Test}

The assumption of a parallel trend is a condition that must be satisfied when building the double-difference model. Based on 2011, generate a series of interactive items pre_3, pre_2, pre_1, constant, post_1, post_2, post_3, indicating the difference between the control group and the treatment group. The regression results omit Pre 1 due to the problem of collinearity. When adding a series of interactive items to the original model and carry out the fixed effect regression of panel data, the parallel trend test can realize. Table 5 shows the parallel trend test results.

Table5. Parallel Trend Test

\begin{tabular}{|c|c|c|c|}
\hline Variable & Coef. & t & $\mathbf{P}>|\mathbf{t}|$ \\
\hline group & 0 & - & $\longrightarrow$ \\
\hline period & 0.2211578 & $3.15^{* * *}$ & 0.004 \\
\hline pre_3 & 0.0081727 & 0.16 & 0.873 \\
\hline pre_2 & 0.0132469 & 0.27 & 0.788 \\
\hline current & -0.123165 & $-2.30 * *$ & 0.029 \\
\hline post_1 & -0.1035881 & $-2.01 *$ & 0.055 \\
\hline post_2 & -0.0381451 & -0.55 & 0.586 \\
\hline post_3 & -0.0422029 & -0.71 & 0.485 \\
\hline $\operatorname{lninv}$ & 0.1691333 & $2.64 * * *$ & 0.013 \\
\hline lnworker & 0.0523247 & 1.34 & 0.191 \\
\hline lnroad & 0.0906405 & 0.97 & 0.340 \\
\hline $\operatorname{lnfin}$ & 0.2249075 & $1.72 *$ & 0.097 \\
\hline indstr & -0.0618078 & -0.48 & 0.635 \\
\hline cons & 2.170764 & 2.31 & 0.029 \\
\hline
\end{tabular}

In Table 5, pre_2 and pre_3 represent the regression analysis of 2009 and 2008 before the opening of HSR. Post_1, post_2, post_3 and post_4 represents the regression analysis of $2011,2012,2013$ and 2014 respectively after the opening of HSR. The coefficient of Pre_2 and pre_3 is insignificant, indicating that the control group and the treatment group possessed a parallel trend before the opening of the BSHSR. The coefficient of current and post_1 is significant and negative, which indicates that the opening of BSHSR has produced a significant adverse effect, which makes the treatment group and the control group appear different trends. The coefficient of post_3 and post_4 is negative but insignificant, and the coefficient is smaller than that the previous two periods, indicating that the negative effect brought by the opening of HSR is gradually weakening. Fig. 2 further presents the dynamic economic effect of opening HSR in different years.

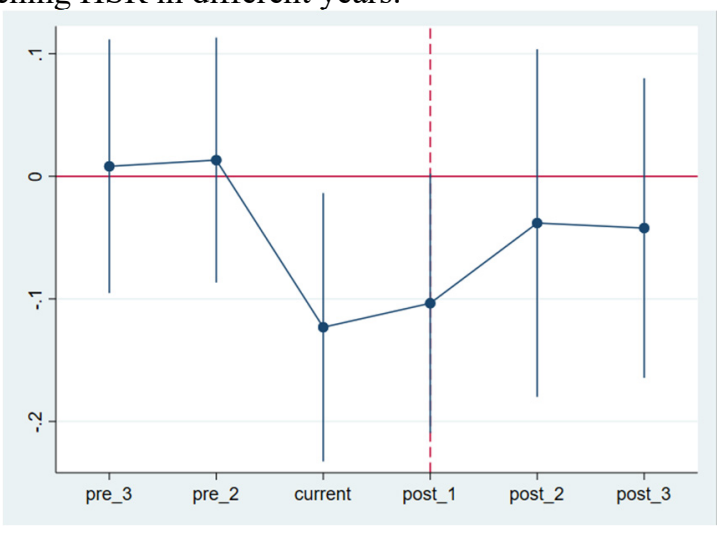

Fig2. Parallel Trend Test

\subsection{Robustness Check}

In order to further ensure the robustness of the model, the next step is to conduct the placebo test. That is, fabricate the open time of HSR, re-estimate its impact on the economic growth around the line, and test whether the economic development of cities along the HSR is only caused by the opening of HSR. If the coefficient of the interaction term is still significant under the fictitious mode, it shows that the original estimation result is likely to be biased, and the economic changes of the regions along the line are likely to be affected by other policy changes or random factors. If the interaction term's coefficient is statistically insignificant under the fictitious mode, the doubt can be eliminated. In this paper, the opening time of HSR is set in 2009 and 2010 respectively. Table 6 shows the estimated results of the DID model.

Table6. Robustness Check Results

\begin{tabular}{|c|c|c|c|}
\hline \multirow{2}{*}{ Variable } & \multicolumn{3}{|c|}{ The open time of the HSR } \\
\cline { 2 - 4 } & $\mathbf{2 0 0 9}$ & $\mathbf{2 0 1 0}$ & $\mathbf{2 0 1 1}$ \\
\hline \multirow{2}{*}{ group } & $\begin{array}{c}0 \\
(.)\end{array}$ & $\begin{array}{c}0 \\
(.)\end{array}$ & $\begin{array}{c}0 \\
(.)\end{array}$ \\
\hline \multirow{2}{*}{ period } & $\begin{array}{c}0.0548774 \\
(1.39)\end{array}$ & $\begin{array}{c}0.1528951 \\
(4.24) * * *\end{array}$ & $\begin{array}{c}0.202181 \\
(6.60) * * *\end{array}$ \\
\hline \multirow{2}{*}{ group $\times$ period } & $\begin{array}{c}-0.0895215 \\
(-0.83)\end{array}$ & $\begin{array}{c}-0.11218 \\
(-1.08)\end{array}$ & $\begin{array}{c}-0.0844506 \\
(-2.68) * * *\end{array}$ \\
\hline \multirow{2}{*}{ lninv } & $\begin{array}{c}0.2189819 \\
(4.01) * * *\end{array}$ & $\begin{array}{c}0.2008113 \\
(3.91) * * *\end{array}$ & $\begin{array}{c}0.1952182 \\
(4.11) * * *\end{array}$ \\
\hline \multirow{2}{*}{ lnworker } & $\begin{array}{c}0.1270107 \\
(2.97) * * *\end{array}$ & $\begin{array}{c}0.1290174 \\
(3.18) * * *\end{array}$ & $\begin{array}{c}0.0699783 \\
(1.80) *\end{array}$ \\
\hline
\end{tabular}




\begin{tabular}{|c|c|c|c|}
\cline { 2 - 4 } Inroad & $\begin{array}{c}0.1138752 \\
(2.09) * *\end{array}$ & $\begin{array}{c}0.1217433 \\
(2.33) * *\end{array}$ & $\begin{array}{c}0.0976411 \\
(1.97) * *\end{array}$ \\
\hline \multirow{2}{*}{ Infin } & $\begin{array}{c}0.3208006 \\
(6.99) * * *\end{array}$ & $\begin{array}{c}0.2445665 \\
(5.05) * * *\end{array}$ & $\begin{array}{c}0.217203 \\
(4.93) * * *\end{array}$ \\
\hline indstr & $\begin{array}{c}-0.0237234 \\
(-0.23)\end{array}$ & $\begin{array}{c}-0.0195505 \\
(-0.20)\end{array}$ & $\begin{array}{c}-0.0224126 \\
(-0.24)\end{array}$ \\
\hline _cons & $\begin{array}{c}-1.316476 \\
(-1.92) *\end{array}$ & $\begin{array}{c}-0.1314979 \\
(-0.18)\end{array}$ & $\begin{array}{c}1.502094 \\
(1.98) * *\end{array}$ \\
\hline
\end{tabular}

Note: *** means significant at $1 \%, * *$ at $5 \%$, and $*$ at $10 \%$.

In table 6, the effect of HSR in 2009 and 2010 was negative but insignificant, while that in 2011 was negative and significant, which indicates that the HSR effect is significant negative only after the opening of BSHSR, which further verifies that one of the reasons for the economic fallout of the areas along the line is the HSR. At the same time, it demonstrates that fixed assets investment, labour force, road area and financial expenditure have a significant positive impact on the regional economic growth always. The industrial structure harms economic growth, but it is not significant.

\section{Conclusions and Suggestions}

This paper selects the opening of BSHSR as a quasinatural experiment and uses the panel data of prefecturelevel cities along the line from 2008 to 2014 and the double-difference model with fixed effect. From the above discussion, one may conclude that the opening of BSHSR harms the per capita GDP of prefecture-level cities along the line in the short term, which is mainly because the agglomeration effect is greater than the diffusion effect. According to the research results above, this paper puts forward several suggestions as following:

First, the construction of large-scale transportation infrastructure, such as HSR, must be adaptive and consistent with the needs of economic development. The local government should take the economic development level and resources and environment constraints into full consideration in HSR's construction plan. It is harmful to blindly seek speed and make the construction far beyond the regional capital and environmental bearing capacity. Trying to avoid the situation of lacking funds caused by the excessive investment on the HSR, it will lead that the region misses the opportunity to develop other industries and hinder the regional economic development. Also, it is inadvisable to be timid and miss an excellent opportunity for development. In short, the development of HSR should thoroughly combine with the actual situation of the region, adjust measures according to local conditions, and formulate the construction plan in line with the regional development.

Second, from the perspective of our country, the construction plan of HSR should fully consider the economic distribution effect of transportation infrastructure. Central and local governments should figure out fiscal transfer payment policy and industrial policy to support the region, strengthen the convergence and combination development of HSR and other forms of transportation, weaken the HSR's agglomeration effect and promote the coordinated development of prefecture- level cities and regional central cities.

Third, from the perspective of small and medium-sized cities along the HSR, local governments should establish the awareness of opportunities and challenges, and actively think about how to response the agglomeration effect of brought by HSR. First of all, we should take full advantage of the HSR's bond function, strengthen exchanges with regional central cities and strive to enlarge the diffusion effect on the contrary. They need to tightly integrate their development with central cities, give full play to local comparative advantages, optimize industrial layout, and complement each other with central cities. Secondly, faced with the agglomeration effect of HSR, they should make efforts to create an anti-agglomeration effect. They should take advantage of the situation of high barriers to settle down and relative saturation of ordinary talents in big cities, speed up the formulation of new talent introduction policy and improve the development system of qualified people, to meet the demands of the era of HSR. The local government also need to encourage and support local enterprises to speed up the introduction of scarce talents and build a comparative advantage of qualified people. Finally, when the HSR has opened to traffic, spatial location is no longer the primary factor of the industrial transfer. Local governments must strive to improve the quality of government services, provide supporting industrial policies, stabilize the market order, and enhance the comprehensive environmental competitiveness.

\section{Acknowledgment}

I want to express gratitude to my classmate, Li Ruimin. She gives me lots of advices on models and stata selflessly and generously.

\section{References}

1. Ahlfeldt, G.M., Feddersen, A., 2010. From periphery to core: economic adjustments to high speed rail. Lse Res. Online Docu. Econ.(38).

2. Fang, D., Sun M., 2016. Evaluation of the impact of high-speed railway on the economic development of Yangtze River Delta Urban Agglomeration: An Empirical Study Based on DID model [J]. Eastern China economic management, 30 (2): 42-47 (in Chinese)

3. Jia, S., Zhou, C., Qin, C., 2017. No difference in effect of high-speed rail on regional economic growth based on match effect perspective? Transport. Res. Part A 106, 144-157.

4. Li H., Fan D., Zhang S., 2020. Analysis of spillover effect of China's high speed rail construction on real economy development [J]. East China economic management, 34 (04): 54-69 (in Chinese)

5. Vickerman, \& R. (1997). High-speed rail in Europe: experience and issues for future development. Annals of Regional Science.

6. Wang, Y., Nian, M., 2014. Does high-speed railway 
drive regional economic development? [J]. Shanghai Economic Research, (02): 82-91 (in Chinese)

7. Zhang K., Tao D., 2016. The economic distribution effect of transportation infrastructure: evidence from the opening of high-speed rail $[\mathrm{J}]$. Economic trends, (6): 62-73 (in Chinese)

8. Wang, C., Meng, W., Hou, X., 2020. The impact of high-speed rails on urban economy: an investigation using night lighting data of Chinese cities. Research in Transportation Economics, 80. 